\title{
Oral Health, Obesity Status and Nutritional Habits in Turkish Children and Adolescents: An Epidemiological Study
}

\author{
Servet Kesim ${ }^{1}$, Betül Çiçek ${ }^{2}$, Cüneyt Asım Aral ${ }^{3}$, Ahmet Öztürk $^{4}$, Mümtaz Mustafa Mazıcıoğlu ${ }^{5}$, \\ Selim Kurtoğlu ${ }^{6}$
}

\author{
${ }^{1}$ Department of Periodontology, Erciyes University School of Dentistry, Kayseri, Turkey \\ ${ }^{2}$ Department of Nutrition and Dietetics, Erciyes University School of Health Sciences, Kayseri, Turkey \\ ${ }^{3}$ Department of Periodontology, Şifa University School of Dentistry, İzmir, Turkey \\ ${ }^{4}$ Department of Biostatistics and Medical Informatics, Erciyes University School of Medicine, Kayseri, Turkey \\ ${ }^{5}$ Department of Family Medicine, Erciyes University School of Medicine, Kayseri, Turkey \\ ${ }^{6}$ Department of Pediatrics, Division of Neonatology, Erciyes University School of Medicine, Kayseri, Turkey
}

Background: Studies evaluating the relationship between oral health status and obesity have provided conflicting data. Therefore, there is a great need to investigate and clarify the possible connection in a comprehensive sample.

Aims: To assess the relationship of obesity and oral health status among children and adolescents aged 6 to 17 yearsold.

Study Design: Cross-sectional study.

Methods: Data were obtained from 4,534 children and adolescents (2,018 boys and 2,516 girls). Questionnaires were sent home prior to examination; afterwards, anthropometric and dental data were collected from participants. Community Periodontal Index (CPI) and number of decayed, missing, and filled teeth in the permanent dentition (DMFT), and deciduous dentition (dmft) index were used to measure oral health status. Height, body weight, body mass index (BMI), waist circumference (WC), and body fat percentage were analyzed.

Results: For DMFT scores, healthy (score $=0$ ) girls and boys had significantly higher BMI and WC values than unhealthy (score $>1)$ girls and boys $(p<0.05)$. Healthy girls had higher fat percentage values than unhealthy girls $(p<0.05)$. In terms of CPI scores, healthy boys had lower BMI and WC values than unhealthy boys $(p<0.05)$. According to multiple binary logistic regres- sion results for model 1, BMI predicted DMFT scores in both genders but CPI scores only in boys. No beverage consumption predicted DMFT scores in boys, while milk consumption predicted DMFT scores in girls. No meal skipping predicted CPI scores in boys. For model 2, WC predicted DMFT scores in both genders and CPI scores only in boys. Milk consumption predicted DMFT scores only in girls. No meal skipping predicted CPI scores for both gender $(p<0.05)$. According to DMFT, there were significant differences between the frequencies of the BMI groups (normal weight, overweight and obese) at the age of 7 (girls only), 9, 10, and 16 (boys only) years and overall (only girls) $(\mathrm{p}<0.05)$. According to CPI, significant differences between the frequencies of the BMI groups at the age of 16 (boys only) and 17 (girls only) were seen $(\mathrm{p}<0.05)$.

Conclusion: Periodontal and dental status appears to correlate with nutritional habits and obesity. Obesity and dental/periodontal diseases are multifactorial diseases that follow similar risk patterns and develop from an interaction between chronic conditions originating early in life. It is important for all health professionals to educate patients at risk about the progression of periodontal and dental diseases and the importance of proper oral hygiene.

Keywords: Adolescents, children, nutrition, obesity

This study was presented at the $43^{\text {rd }}$ Scientific Congress of Turkish Periodontology Association, 9-11 May 2013, İmir, Turkey.

Address for Correspondence: Dr. Servet Kesim, Department of Periodontology, Erciyes University School of Dentistry, Kayseri, Turkey 
Obesity is a global health problem and the prevalence of obesity has increased noticeably over the past decades. Obesity is considered a risk factor for some diseases, such as coronary heart disease, hypertension, and type 2 diabetes mellitus (1). Furthermore, epidemiological and case-control studies have shown that obesity, as assessed by body fat, body mass index, waist-to-hip ratio, or waist circumference, is significantly associated with periodontitis (1-5). Thus, conditions associated with obesity may exacerbate periodontal disease.

The severity of periodontitis increases with age $(4,5)$; therefore, it is important to provide periodontal health by controlling risk factors especially in younger populations. To the best of our knowledge, a limited number of studies have investigated body composition as a risk factor for periodontitis in children and adolescents. We aimed to investigate whether an association exists between obesity parametersdetermined by body mass index (BMI), and waist circumference (WC), body fat percentage-and dental and periodontal diseases in children and adolescents aged 6 to 17 years-old.

\section{MATERIALS AND METHODS}

\section{Study design}

Data were acquired from Determination of Anthropometric Measurements in Turkish Children and Adolescents (DAMTCA II) which is a cross-sectional screening study, between September 2007 and June 2008. The survey was performed in the central Anatolian city of Kayseri, which has more than 1.2 million residents. We randomly selected 4,534 children and adolescents (2,018 boys and 2,516 girls) aged 6-17 years from different schools of the central and peripheral regions.

This study was approved by a local ethics committee and conducted in accordance with the Declaration of Helsinki. Parents gave written consent for their children to take part in the study. Permission to perform the study was taken from the Local Governorship, Ministry of Education, and Ministry of Health.

\section{Sampling technique}

A stratified multistage sampling design was used. In the first phase, a random selection was performed of state and private schools that represent the city center and peripheral districts. We randomly selected 47 schools (23 primary and 24 secondary) among 708 schools in Kayseri, Turkey. In the second stage, schools that were grouped by the local educational authority according to socioeconomic status and enrolled children and adolescents from schools' registers underwent simple random sampling. In each school, a previously specified number of children were randomly selected proportionally from each class.

The following inclusion criteria were used for participant selection: no regular drug use, no pathological disturbances in growth and development, age $\geq 6$ years, and the presence of all permanent first molars partially/fully. Individuals with growth disorders or those using any medication were excluded.

\section{Dental examination}

Community Periodontal Index (CPI), number of decayed, missing, and filled teeth in the permanent dentition (DMFT), and deciduous dentition (dmft) index were the parameters used to measure dental and periodontal health. Both $\mathrm{dmft}$ and DMFT measures were used for 6-11 year-old children with mixed dentition. The DMFT was used for adolescents aged $12-17$ years.

Teeth were examined with a mouth mirror and a WHO621 Trinity periodontal probe (Campo Mourão; PR, Brazil). The dentition was divided into six sextants. For each sextant, the highest CPI score was recorded. The highest CPI score was recorded as the final score of the individual. At least six points on each tooth (mesiobuccal, midbuccal, distobuccal, distooral, midoral, and mesiooral) were examined. The data were scored on a scale according to CPI scores as follows: 0 , healthy; 1 , bleeding on gentle probing; 2 , calculus; 3 , shallow pockets of 4 or $5 \mathrm{~mm}$; and 4, pockets of $6 \mathrm{~mm}$ or more (5). Partially erupted teeth, third molars, and retained roots were excluded.

Oral examinations were performed by two trained and calibrated dentists accompanied by their recorders and assistants and undertaken in accordance with World Health Organization criteria (6). The inter-observer correlation coefficient was $\geq 0.91$. Intra-assay coefficients of variability were less than $4 \%$.

\section{Questionnaire}

The questionnaire was sent to participants' homes prior to evaluation. The questionnaire had three sections; a general section focused on self-reported family data such as inhabitation, socio-economic status, and parent-reported level of education, status of employment, and the child's section included media consumption, sleep duration, and nutritional habits.

\section{Anthropometric indices}

Measurements were taken by experienced health technicians. Height was determined using portable stadiometers that were calibrated daily, weight was measured by Tanita (BC- 
TABLE 1. Anthropometric indices of the entire group according to DMFT and CPI scores

\begin{tabular}{|c|c|c|c|c|c|c|c|c|}
\hline \multirow{3}{*}{ Anthropometric indices } & \multicolumn{4}{|c|}{ DMFT } & \multicolumn{3}{|c|}{ CPI } & \\
\hline & \multicolumn{2}{|c|}{ Boys } & \multicolumn{2}{|c|}{ Girls } & \multicolumn{2}{|c|}{ Boys } & \multicolumn{2}{|c|}{ Girls } \\
\hline & $\begin{array}{l}\text { Score }=0 \\
\text { healthy }\end{array}$ & $\begin{array}{l}\text { Score }>0 \\
\text { unhealthy }\end{array}$ & $\begin{array}{c}\text { Score }=0 \\
\text { healthy }\end{array}$ & $\begin{array}{l}\text { Score }=0 \\
\text { unhealthy }\end{array}$ & $\begin{array}{c}\text { Score }=0 \\
\text { healthy }\end{array}$ & $\begin{array}{l}\text { Score }>0 \\
\text { unhealthy }\end{array}$ & $\begin{array}{l}\text { Score }=0 \\
\text { healthy }\end{array}$ & $\begin{array}{l}\text { Score }>0 \\
\text { unhealthy }\end{array}$ \\
\hline & $\overline{\mathrm{X}} \pm s d$ & $\overline{\mathrm{X}} \pm s d$ & $\overline{\mathrm{X}} \pm s d$ & $\overline{\mathrm{X}} \pm s d$ & $\overline{\mathrm{X}} \pm s d$ & $\overline{\mathrm{X}} \pm s d$ & $\overline{\mathrm{X}} \pm s d$ & $\overline{\mathrm{X}} \pm s d$ \\
\hline $\operatorname{BMI}\left(\mathrm{kg} / \mathrm{m}^{2}\right)$ & $20.1 \pm 3.6$ & $18.5 \pm 3.5^{*}$ & $20.6 \pm 3.5$ & $18.9 \pm 3.6^{*}$ & $17.7 \pm 3.8$ & $19.0 \pm 3.6^{*}$ & $19.5 \pm 3.7$ & $19.5 \pm 3.6$ \\
\hline $\mathrm{WC}(\mathrm{cm})$ & $71.2 \pm 10.7$ & $65.2 \pm 10.9 *$ & $68.0 \pm 9.1$ & $63.9 \pm 9.7 *$ & $62.7 \pm 11.1$ & $67.5 \pm 11.2 *$ & $65.5 \pm 8.8$ & $65.5 \pm 9.8$ \\
\hline Fat percentage & $18.6 \pm 6.0$ & $19.0 \pm 5.8$ & $25.0 \pm 6.1$ & $23.8 \pm 5.5^{*}$ & $19.1 \pm 5.0$ & $18.9 \pm 5.6$ & $24.6 \pm 5.9$ & $24.3 \pm 5.8$ \\
\hline
\end{tabular}

* refers to significant difference $(\mathrm{p}<0.05)$ between healthy and unhealthy.

DMFT: number of decayed, missing and filled teeth in the permanent dentition; CPI: community periodontal index; BMI: body mass index; WC: waist circumference

TABLE 2. The univariate and multivariate binary logistic regression analysis related to nutritional variables according to DMFT and CPI scores

\begin{tabular}{|c|c|c|c|c|}
\hline \multirow{2}{*}{$\begin{array}{l}\text { Univariate binary logistic regression } \\
\text { Variables }\end{array}$} & \multicolumn{2}{|c|}{ DMFT } & \multicolumn{2}{|c|}{ CPI } \\
\hline & Boys OR (CI) & Girls OR (CI) & Boys OR (CI) & Girls OR (CI) \\
\hline \multicolumn{5}{|l|}{ Meal skipping } \\
\hline Yes & 1.00 & 1.00 & 1.00 & 1.00 \\
\hline No & $1.14(0.91-1.42)$ & $1.13(0.90-1.43)$ & $0.54(0.34-0.85)^{*}$ & $0.69(0.48-0.99) *$ \\
\hline \multicolumn{5}{|l|}{ Snacking frequency } \\
\hline Never & 1.00 & 1.00 & 1.00 & 1.00 \\
\hline Occasionally & $1.03(0.71-1.49)$ & $0.86(0.64-1.17)$ & $1.12(0.53-2.36)$ & $0.72(0.41-1.25)$ \\
\hline Sometimes & $1.06(0.73-1.53)$ & $0.85(0.62-1.15)$ & $1.12(0.53-2.38)$ & $0.94(0.53-1.66)$ \\
\hline Frequently & $1.04(0.69-1.56)$ & $0.73(0.51-1.05)$ & $1.57(0.65-3.81)$ & $0.58(0.31-1.07)$ \\
\hline Always & $1.31(0.80-2.19)$ & $0.78(0.51-1.20)$ & $2.61(0.69-9.88)$ & $0.74(0.35-1.57)$ \\
\hline Appetite & $0.89(0.80-0.99)^{*}$ & $0.80(0.73-0.88)^{*}$ & $1.60(1.26-2.03)^{*}$ & $0.94(0.80-1.10)$ \\
\hline \multicolumn{5}{|l|}{ Duration of breastfeeding (mo) } \\
\hline Never breastfed & 1.00 & 1.00 & 1.00 & 1.00 \\
\hline 4 & $1.18(0.76-1.82)$ & $1.36(0.95-1.95)$ & $0.63(0.23-1.69)$ & $1.36(0.76-2.42)$ \\
\hline 6 & $0.86(0.57-1.30)$ & $1.12(0.80-1.59)$ & $0.78(0.29-2.07)$ & $1.37(0.78-2.39)$ \\
\hline 12 & $0.99(0.65-1.52)$ & $0.99(0.70-1.40)$ & $0.67(0.25-1.79)$ & $1.14(0.66-1.97)$ \\
\hline $12-24$ & $1.01(0.66-1.55)$ & $1.19(0.83-1.71)$ & $1.09(0.39-3.09)$ & $1.36(0.76-2.43)$ \\
\hline 25 and above & $0.88(0.53-1.45)$ & $1.30(0.79-2.14)$ & $1.47(0.39-5.60)$ & $2.11(0.82-5.47)$ \\
\hline \multicolumn{5}{|l|}{ Beverage consumption } \\
\hline Yes & 1.00 & 1.00 & 1.00 & 1.00 \\
\hline No & $1.31(1.09-1.58)^{*}$ & $1.05(0.89-1.23)$ & $128(0.86-1.90)$ & $0.95(0.72-1.25)$ \\
\hline \multicolumn{5}{|l|}{ Nut consumption } \\
\hline Yes & 1.00 & 1.00 & 1.00 & 1.00 \\
\hline No & $1.22(1.01-1.45)^{*}$ & $0.98(0.84-1.17)$ & $1.45(0.95-2.20)$ & $0.93(0.69-1.23)$ \\
\hline \multicolumn{5}{|l|}{ Fruit consumption } \\
\hline Yes & 1.00 & 1.00 & 1.00 & 1.00 \\
\hline No & $1.02(0.85-1.23)$ & $1.04(0.88-1.22)$ & $1.45(0.98-2.17)$ & $1.13(0.86-1.50)$ \\
\hline \multicolumn{5}{|l|}{ Milk consumption } \\
\hline No & 1.00 & 1.00 & 1.00 & 1.00 \\
\hline Yes & $1.08(0.89-1.31)$ & $1.30(1.09-1.54)^{*}$ & $1.48(0.97-2.27)$ & $0.94(0.70-1.25)$ \\
\hline \multicolumn{5}{|l|}{ Sweet consumption } \\
\hline No & 1.00 & 1.00 & 1.00 & 1.00 \\
\hline Yes & $1.07(0.89-1.28)$ & $1.11(0.94-1.31)$ & $1.09(0.74-1.64)$ & $0.89(0.67-1.19)$ \\
\hline
\end{tabular}


TABLE 2. Continued

\begin{tabular}{|c|c|c|c|c|}
\hline \multicolumn{5}{|c|}{ Fresh vegetable consumption } \\
\hline No & 1.00 & 1.00 & 1.00 & 1.00 \\
\hline Yes & $0.92(0.77-1.11)$ & $1.13(0.96-1.33)$ & $0.65(0.43-0.96)^{*}$ & $0.98(0.75-1.30)$ \\
\hline \multicolumn{5}{|c|}{ Salty biscuit consumption } \\
\hline No & 1.00 & 1.00 & 1.00 & 1.00 \\
\hline Yes & $1.06(0.89-1.28)$ & $0.89(0.76-1.04)$ & $1.26(0.85-1.88)$ & $0.87(0.66-1.14)$ \\
\hline \multicolumn{5}{|c|}{ Anthropometric indices } \\
\hline BMI & $0.89(0.87-0.91)^{*}$ & $0.88(0.86-0.90)^{*}$ & $1.14(1.07-1.23)^{*}$ & $1.00(0.96-1.04)$ \\
\hline $\mathrm{WC}$ & $0.95(0.94-0.96)^{*}$ & $0.95(0.94-0.96)^{*}$ & $1.05(1.02-1.09)^{*}$ & $1.00(0.99-1.01)$ \\
\hline Fat percentage $(\%)$ & $1.01(0.99-1.03)$ & $0.96(0.95-0.98)^{*}$ & $0.99(0.96-1.03)$ & $0.99(0.97-1.01)$ \\
\hline \multicolumn{5}{|c|}{$\begin{array}{l}\text { Multiple binary logistic regression } \\
\text { (hierarchical backward elimination procedure) }\end{array}$} \\
\hline \multicolumn{5}{|l|}{ Model 1 (BMI) } \\
\hline BMI & $0.89(0.87-0.92)^{*}$ & $0.88(0.86-0.90)^{*}$ & $1.14(1.05-1.24)^{*}$ & - \\
\hline \multicolumn{5}{|l|}{ Beverage consumption } \\
\hline Yes & 1.00 & - & - & - \\
\hline No & $1.23(1.01-1.49)^{*}$ & - & - & - \\
\hline \multicolumn{5}{|l|}{ Milk consumption } \\
\hline No & - & 1.00 & - & - \\
\hline Yes & - & $1.19(1.01-1.43)^{*}$ & - & - \\
\hline \multicolumn{5}{|l|}{ Meal skipping } \\
\hline Yes & - & - & 1.00 & - \\
\hline No & - & - & $0.54(0.34-0.86)^{*}$ & - \\
\hline \multicolumn{5}{|l|}{ Model 2 (WC) } \\
\hline $\mathrm{WC}$ & $0.95(0.94-0.96)^{*}$ & $0.95(0.95-0.96)^{*}$ & $1.04(1.02-1.07)^{*}$ & - \\
\hline Milk consumption & & & & - \\
\hline No & - & 1.00 & - & - \\
\hline Yes & - & $1.21(1.01-1.44)^{*}$ & - & - \\
\hline \multicolumn{5}{|l|}{ Meal skipping } \\
\hline Yes & - & - & 1.00 & 1.00 \\
\hline No & - & - & $0.54(0.34-0.85)^{*}$ & $0.69(0.48-0.99)^{*}$ \\
\hline
\end{tabular}

Values represent OR (Odds Ratio) [95\% (CI)] adjusted for age; *p $<0.05$

DMFT: number of decayed, missing and filled teeth in the permanent dentition; CPI: community periodontal index; BMI: body mass index; WC: waist circumference; CI: confidence interval

418; Tanita Corp.; Tokyo, Japan). Weight, height, and waist circumference (WC) were measured twice, and the average was recorded. WC was measured with the individual in standing position at the end of expiration. The BMI was calculated according to the formula: weight $(\mathrm{kg}) /$ height $(\mathrm{m})^{2}$. Body fat percentage was measured by bioelectrical impedance analysis (BIA). The Tanita Segmental Body Composition Analyzer was used for BIA, which can provide separate body mass analyses for different segments of the body.

Children were asked not to drink or eat and to empty their bladders in the hour prior to measurements. The researchers entered information on children's age, gender, height, and body type, and estimated percent body fat equations for children were displayed by the machine.

\section{Statistical analysis}

Student's t-test was used to determine differences in the DMFT and CPI scores between healthy and unhealthy. Chi-square test was used to detect the relationship between DMFT/CPI scores within each gender and age. Binary logistic regression analyses were used to assess the risk factors to influence CPI and DMFT scores. Significant variables at $\mathrm{p}<0.05$ were included to multiple model and backward elimination was performed using the Wald statistic. 


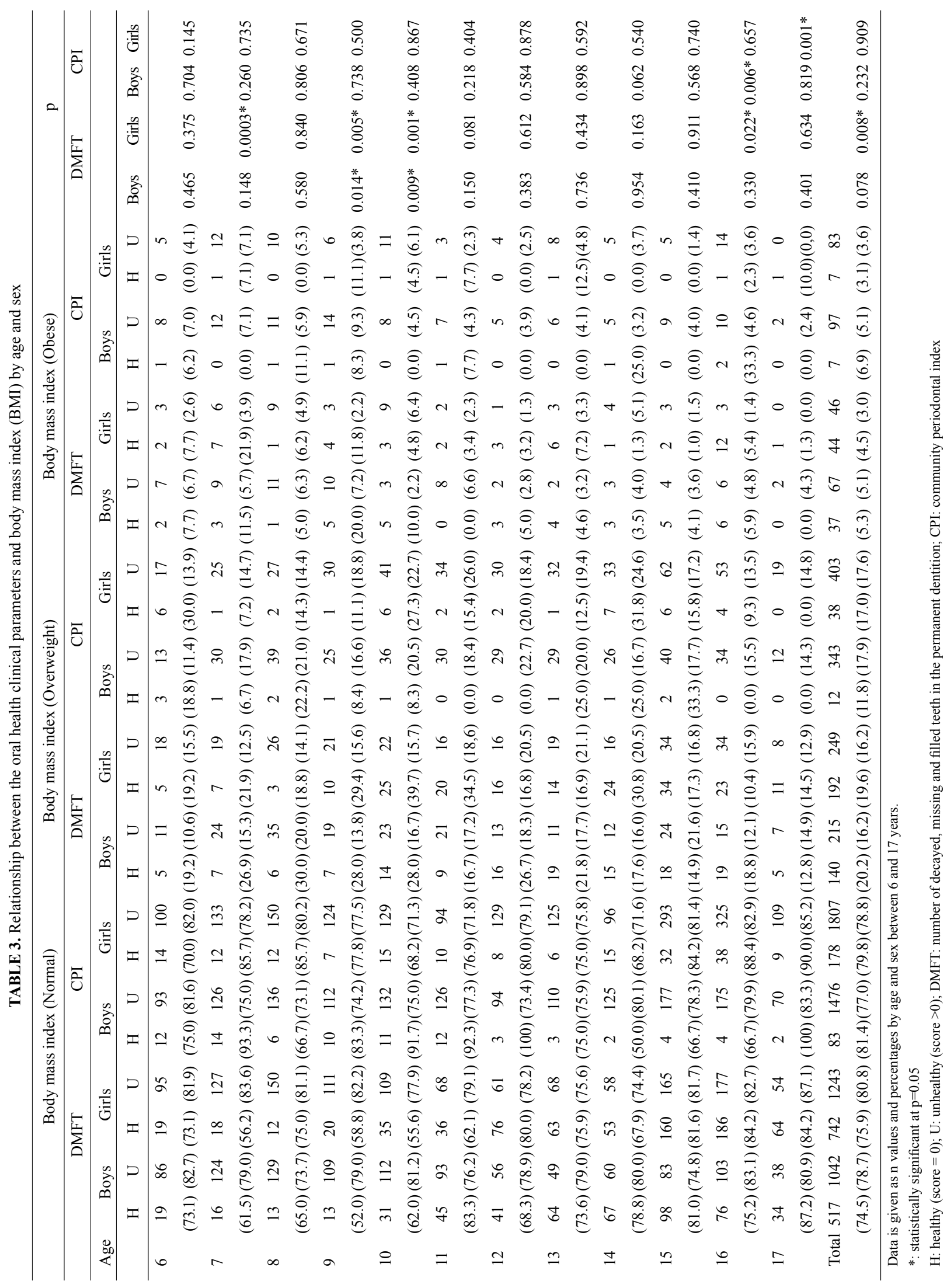


Odds ratios were calculated using 95\% confidence intervals. Intraclass correlation coefficient (ICC) was used to evaluate the intra- and inter-examiner reliability of DMFT, CPI and anthropometric indices. Data were analyzed with a statistical software program (R 2.14.0, The R Foundation; Vienna, Austria). Differences were considered to be statistically significant when $\mathrm{p}<0.05$.

\section{RESULTS}

The inter-examiner ICC scores were $0.82,0.85$, and 0.91 for DMFT, CPI and anthropometric indices, respectively. Furthermore, the intra-examiner ICC scores were $0.87,0.89$, and 0.93 for DMFT, CPI and anthropometric indices, respectively.

Table 1 shows the anthropometric indices of the entire group according to DMFT and CPI scores. For DMFT scores, healthy $($ score $=0)$ girls and boys had significantly higher $\mathrm{BMI}$ and $\mathrm{WC}$ values than unhealthy (score $>1$ ) girls and boys $(p<0.05)$. Healthy girls had higher fat percentage values than unhealthy girls $(\mathrm{p}<0.05)$. In terms of CPI scores, healthy boys had lower BMI and WC values than unhealthy boys $(\mathrm{p}<0.05)$.

Table 2 shows the univariate and multiple binary logistic regression analysis related to nutritional variables according to DMFT and CPI scores. No meal skipping significantly determined CPI scores in both genders. Appetite significantly predicted DMFT scores in both genders and CPI scores only in boys. No beverage and no nut consumption significantly predicted DMFT scores only in boys. Milk consumption significantly predicted DMFT scores only in girls. Fresh vegetable consumption significantly predicted CPI scores only in boys.

Of the anthropometric indices, DMFT scores were significantly associated with BMI and WC in both genders, while CPI scores were significant for these indices only among boys. DMFT scores were significantly associated with fat percentage only among girls.

According to multiple binary logistic regression results for model 1 (BMI), BMI significantly predicted DMFT scores in both genders and CPI scores only in boys. No beverage consumption significantly predicted DMFT scores only in boys. Milk consumption significantly predicted DMFT scores only in girls. No meal skipping significantly predicted CPI scores only in boys. For model 2 (WC), WC significantly predicted DMFT scores in both genders and CPI scores only in boys. Milk consumption significantly predicted DMFT scores only in girls. No meal skipping significantly predicted CPI scores in both genders.

Table 3 shows the $\mathrm{n}$ values and percentages according to DMFT, CPI, and normal weight, overweight, and obese participants between 6 and 17 years by age and sex. According to DMFT, there was a significant difference between the frequencies of the three BMI groups at the age of 7 (girls only), 9, 10 , and 16 (boys only) years and overall (only girls) $(\mathrm{p}<0.05)$. According to CPI, there were significant differences between the frequencies of the BMI groups at the age of 16 (boys only) and 17 (girls only) $(\mathrm{p}<0.05)$.

\section{DISCUSSION}

This study has several noteworthy advantages. To our knowledge, it is the most extensive study, with a large sample size and a wide age range that assesses both DMFT and CPI scores as well as WC and body fat percentage values, in addition to conventional anthropometric indices like BMI.

\section{DMFT scores and obesity}

In this study, DMFT scores showed that healthy boys and girls had significantly higher BMI than unhealthy boys and girls. Similar findings were noted for WC. Healthy girls had higher fat percentage values than unhealthy girls (Table 1). Furthermore, DMFT was significantly related to the frequencies of the three BMI groups at the age of 7 (girls only), 9, 10, and 16 (boys only) years, and overall (girls only) (Table 3 ).

Studies on the interrelation between DMFT and obesity in school-aged children have produced conflicting data. Recent studies investigating this relationship have found a positive correlation between high DMFT and obesity (7-11), whereas a study described an inverse relationship (12), and some studies found no association (13-15).

Investigation into the interrelation between DMFT and obesity in deciduous teeth has also been inconclusive. Overweight children were found to have higher indexes of dental caries than normal weight subjects in Italy $(10,11)$. Additionally, BMI percentile did not correlate with dmft in children aged $\geq 2$ years in the USA $(16,17)$. Controversially, overweight children had a lower dmft index, compared to children with a lower BMI in Mexico (18).

In a recent study conducted in Turkey, in 7,833 individuals of different ages, caries prevalence (according to DMFT) was higher among girls than among boys (19). However, this study did not classify the children as normal or overweight. Thus, to our knowledge, this is the first study to demonstrate the association between DMFT scores and obesity in children and adolescents in a Turkish population.

The association between DMFT and obesity among schoolaged children remains unclear, as these two parameters in all pre-adolescents may indicate that obesity and DMFT share similar underlying factors, regardless of age, nationality, socio-economic differences, and differing oral healthcare habits. 


\section{CPI scores and obesity}

Community Periodontal Index has been extensively used in epidemiological studies and in clinical practice for screening for periodontal disease. It is accepted worldwide and preferred over other markers because of its practicability, simplicity, and repeatability.

A previous study showed a relationship between visceral fat area-defined obesity and periodontitis in people aged $\geq 15$ years (1). Additionally, some studies have investigated the association between CPI scores and BMI and/or WC and/ or body fat percentage in children and young adults $(20,21)$. However, none evaluated the association between children's CPI scores and BMI, WC, and body fat percentage together in children and adolescents. Thus, we could not compare our data to those of national or international studies.

In our study on CPI scores, healthy boys had lower BMI and WC values than unhealthy boys, while healthy and unhealthy girls had similar BMI and WC values (Table 1). Additionally, there were significant differences between CPI and the frequencies of the three BMI groups in participants aged 16 (boys only) and 17 (girls only) years (Table 3). Several studies have shown an association between periodontitis and central obesity indicators such as BMI and WC. Among Koreans aged $\geq 15$ years, BMI, WC, and visceral fat area were associated with the number of sextants with periodontitis (1). Among US adolescents aged 17-21 years, increased body weight and WC were associated with higher risk of periodontal disease. However, for adolescents aged 13-16 years, no relationship was found between WC or weight and periodontitis risk (22). In another study, a higher BMI was associated with increased risk of periodontitis in 18-24-year-old Japanese university students (5). Saito et al. (2) reported that the waist-to-hip ratio is associated with periodontitis regardless of BMI and body fat. In their study, 18 to 34 year old young adults with a high BMI had an increased risk for periodontal disease, and those with a large WC were even more at risk of disease (3). These results suggest that periodontitis may be an age-dependent disease associated with extensive fat accumulated during childhood and adolescence, but which is clinically recognizable in adulthood. Furthermore, there is no study examining the interaction between obesity and periodontitis among Turkish children and adolescents. Therefore, this research aimed to provide evidence on the association between obesity and periodontitis in Turkish population.

In this study, BMI and WC significantly predicted CPI scores in boys. A previous study reported a significant correlation between both BMI and WC and CPI in women, while the relationship between WC and CPI was only seen in young male adults (23). In another study, visceral fat area and periodontitis were significantly associated in men aged 45-54 years (1). Further epidemiological studies are needed to clarify this discrepancy between associations seen in men and women.
Most studies have shown correlations between periodontitis and obesity indices like BMI, WC, waist-to-hip ratio, and fat percent. Hence, we initially added fat percentage results from BIA measurements as an obesity index to determine the relationship between obesity and dental/periodontal disease among a Turkish population. There are two studies using BIA to monitor body compositions such as BMI and body fat percentage in adolescents aged $\geq 15$ years $(24,25)$. To our knowledge, this is the first study to provide BIA results as an obesity indicator to reveal a link between periodontitis and obesity in 6-17 year-old children and adolescents.

Visceral fat deposits that frequently occur in abdominal obesity increase the risk of certain diseases. Han et al. (1) and Saito et al. (2) showed a positive relation between visceral fat accumulation and periodontitis. Various potential mechanisms could account for this association. Overweight adolescents may have unhealthy and inadequate nutrition as well as excess sugar and fat content, which increase periodontal disease risk. Poor dietary patterns such as low calcium and vitamin $\mathrm{C}$ intake may affect oral tissues and immune response. Additional possible mechanisms may include alterations in host immune responses and/or increased stress levels, often related to gaining excess fat early in life. Visceral fat deposit may play a role in periodontitis progression through the release of various inflammatory mediators. Adipose tissue itself acts like an endocrine organ producing several proteins (e.g., adipokines).

In this study, according to CPI, healthy boys have lower BMI and WC, but higher body fat percentage than unhealthy boys, and according to DMFT, an inverse relationship was found, although body fat percentage differences were not significant (Table 1). BMI can indicate different levels of body fatness in particular ethnic groups (26). Furthermore, WC and BMI are correlated with each other, more so than with body fat percentage for all sex-age groups (27). Therefore, BMI and locational assessment body fat may show controversial relationships. Further studies are required to clarify the correlation between BMI and body fat percentage in periodontal- and dental-compromised individuals and determine whether daily activities and nutritional habits may affect CPI and DMFT scores and influence body fat percentages.

\section{Nutritional habits and DMFT and CPI scores}

In this study, nutritional habits such as no meal skipping, appetite, no beverage, nut, milk, and fresh vegetable consumption and mean appetite scores significantly predicted DMFT and/or CPI scores for healthy/unhealthy boys and/or girls (Table 2).

The separate clustering of milk consumption and snacking on fresh vegetables resulted in a significant difference in DMFT among girls and CPI among boys. Ngoenwiwatkul and Leela-adisorn (28) reported similar food and beverage consump- 
tions (sweetened milk and snacks) as the top two contributors to BMI-for-age $\left(<15^{\text {th }}\right.$, and $\geq 15^{\text {th }}$ percentile $)$ among first-grade primary school children. Additionally, daily total energy, total carbohydrate, total fat, and total sugar intakes were higher in the caries-present group than in the caries-free group (29). Furthermore, a significant association was detected between DMFT and sugar consumption, but not with BMI, in 12-year-old French children (30).

Another contributor of obesity and overweight is the increased dietary fat intake. In this case, overconsumption of fatty foods has less influence on caries development than the consumption of a sugary diet. This may explain the lack of association between obesity and caries.

\section{CONCLUSION}

Given the importance of overweight as a public health problem, medical and dental professionals should assess health/risk behaviors, connections between oral and systemic health, and make interdisciplinary communications for diagnosing and treating precocious signs of dental/periodontal diseases among children and adolescents. Additionally, it is important to consider including routine oral health in education and healthcare programs.

Since measuring WC and calculating BMI are simple and accurate methods for identifying youth at risk for obesity, such data can be used by healthcare professionals to build a risk profile for dental caries and related situations, especially in high-risk populations.

These results indicate that nutritional habits may predispose children/adolescents to high CPI and/or DMFT scores. For example, no meal skipping may determine CPI scores, and appetite may predict DMFT scores in both genders. Longitudinal studies can further explore these associations in children and adolescents, such as whether oral hygiene, metabolic disorders and dietary habits, and behavioral practices influence dental and periodontal disease.

Ethics Committee Approval: Ethics committee approval was received for this study from the ethics committee of Erciyes University.

Informed Consent: Written informed consent was obtained from patients who participated in this study.

Peer-review: Externally peer-reviewed.

Author contributions: Concept - S.K., B.Ç., M.M.M.; Design - S.K., B.Ç.; Supervision - S.K.; Resource - S.K., B.Ç., C.A.A., M.M.M., S.Kurtoğlu; Materials - S.K., C.A.A., B.Ç., M.M.M.; Data Collection and/or Processing - S.K., B.Ç., C.A.A.; Analysis and/or Interpretation - S.K., B.Ç., A.Ö.; Literature Search - S.K.; Writing - S.K., B.Ç.; Critical Reviews - S.K., B.Ç., C.A.A., A.Ö.
Conflict of Interest: No conflict of interest was declared by the authors.

Financial Disclosure: The authors declared that this study has received no financial support.

\section{REFERENCES}

1. Han DH, Lim SY, Sun BC, Paek DM, Kim HD. Visceral fat area-defined obesity and periodontitis among Koreans. $J$ Clin Periodontol 2010;37:172-9. [CrossRef]

2. Saito T, Shimazaki Y, Koga T, Tsuzuki M, Ohshima A. Relationship between upper body obesity and periodontitis. J Dent Res 2001;80:1631-6. [CrossRef]

3. Al-Zahrani MS, Bissada NF, Borawski EA. Obesity and periodontal disease in young, middle-aged, and older adults. J Periodontol 2003;74:610ç-5.

4. Albandar JM, Tinoco EM. Global epidemiology of periodontal diseases in children and young persons. Periodontol 2000 2002;29:153-76. [CrossRef]

5. Ekuni D, Yamamoto T, Koyama R, Tsuneishi M, Naito K, Tobe K. Relationship between body mass index and periodontitis in young Japanese adults. J Periodontal Res 2008;43:417-21. [CrossRef]

6. Oral Health Surveys, Basic Methods, 4th ed.: Geneva: WHO.; 1997 [cited 2011 December 21st]. Available from: http://whqlibdoc.who.int/publications/1997/9241544937.pdf.

7. Willerhausen B, Blettner M, Kasaj A, Hohenfellner K. Association between body mass index and dental health in 1,290 children of elementary schools in a German city. Clin Oral Investig 2007;11:195-200. [CrossRef]

8. Qadri G, Alkilzy M, Feng YS, Splieth C. Overweight and dental caries: the association among German children. Int $J$ Paediatr Dent 2014.

9. Sakeenabi B, Swamy HS, Mohammed RN. Association between obesity, dental caries and socioeconomic status in 6- and 13-yearold school children. Oral Health Prev Dent 2012;10:231-41.

10. Costacurta M, Di Renzo L, Bianchi A, Fabiocchi F, De Lorenzo A, Docimo R. Obesity and dental caries in paediatric patients. A cross-sectional study. Eur J Paediatr Dent 2011;12:112-6.

11. Costacurta M, DiRenzo L, Sicuro L, Gratteri S, De Lorenzo A, Docimo R. Dental caries and childhood obesity: analysis of food intakes, lifestyle. Eur J Paediatr Dent 2014;15:343-8.

12. Macek MD, Mitola DJ. Exploring the association between overweight and dental caries among US children. Pediatr Dent 2006;28:375-80.

13. Pinto A, Kim S, Wadenya R, Rosenberg H. Is there an association between weight and dental caries among pediatric patients in an urban dental school? A correlation study. J Dent Educ 2007;71:1435-40.

14. Freitas AR, Aznar FD, Tinos AM, Yamashita JM, Sales-Peres A, Sales-Peres SH. Association between dental caries activity, quality of life and obesity in Brazilian adolescents. Int Dent J 2014;64:318-23. [CrossRef] 
15. Cinar AB, Christensen LB, Hede B. Clustering of obesity and dental caries with lifestyle factors among Danish adolescents. Oral Health Prev Dent 2011;9:123-30.

16. Sohn W. Obese or overweight children do not have a higher risk of dental caries. J Evid Based Dent Pract 2009;9:97-8. [CrossRef]

17. Sheller B, Churchill SS, Williams BJ, Davidson B. Body mass index of children with severe early childhood caries. Pediatr Dent 2009;31:216-21.

18. Sanchez-Perez L, Irigoyen ME, Zepeda M. Dental caries, tooth eruption timing and obesity: a longitudinal study in a group of Mexican schoolchildren. Acta Odontol Scand 2010;68:57-64. [CrossRef]

19. Gokalp SG, Dogan BG, Tekcicek MT, Berberoglu A, Unluer S. National survey of oral health status of children and adults in Turkey. Community Dent Health 2010;27:12-7.

20. Scorzetti L, Marcattili D, Pasini M, Mattei A, Marchetti E, Marzo G. Association between obesity and periodontal disease in children. Eur J Paediatr Dent 2013;14:181-4.

21. Irigoyen-Camacho ME, Sanchez-Perez L, Molina-Frechero N, Velazquez-Alva C, Zepeda-Zepeda M, Borges-Yanez A. The relationship between body mass index and body fat percentage and periodontal status in Mexican adolescents. Acta Odontol Scand 2014;72:48-57. [CrossRef]

22. Reeves AF, Rees JM, Schiff M, Hujoel P. Total body weight and waist circumference associated with chronic periodontitis among adolescents in the United States. Arch Pediatr Adolesc Med 2006;160:894-9. [CrossRef]

23. Amin Hel S. Relationship between overall and abdominal obesity and periodontal disease among young adults. East Mediterr Health J 2010;16:429-33.
24. Irigoyen-Camacho ME, Sanchez-Perez L, Molina-Frechero N, Velazquez-Alva C, Zepeda-Zepeda M, Borges-Yanez A. The relationship between body mass index and body fat percentage and periodontal status in Mexican adolescents. Acta Odontol Scand 2014;72:48-57. [CrossRef]

25. Wood N, Johnson RB, Streckfus CF. Comparison of body composition and periodontal disease using nutritional assessment techniques: Third National Health and Nutrition Examination Survey (NHANES III). J Clin Periodontol 2003;30:321-7. [CrossRef]

26. Wang J, Thornton JC, Russell M, Burastero S, Heymsfield S, Pierson RN, Jr. Asians have lower body mass index (BMI) but higher percent body fat than do whites: comparisons of anthropometric measurements. Am J Clin Nutr 1994;60:23-8.

27. Flegal KM, Shepherd JA, Looker AC, Graubard BI, Borrud LG, Ogden CL, et al. Comparisons of percentage body fat, body mass index, waist circumference, and waist-stature ratio in adults. Am J Clin Nutr 2009;89:500-8. [CrossRef]

28. Ngoenwiwatkul Y, Leela-adisorn N. Effects of dental caries on nutritional status among first-grade primary school children. Asia Pac J Public Health 2009;21:177-83. [CrossRef]

29. Hong L, Ahmed A, McCunniff M, Overman P, Mathew M. Obesity and dental caries in children aged 2-6 years in the United States: National Health and Nutrition Examination Survey 1999-2002. J Public Health Dent 2008;68:227-33. [CrossRef]

30. Tramini P, Molinari N, Tentscher M, Demattei C, Schulte AG. Association between caries experience and body mass index in 12-year-old French children. Caries Res 2009;43:468-73. [CrossRef] 